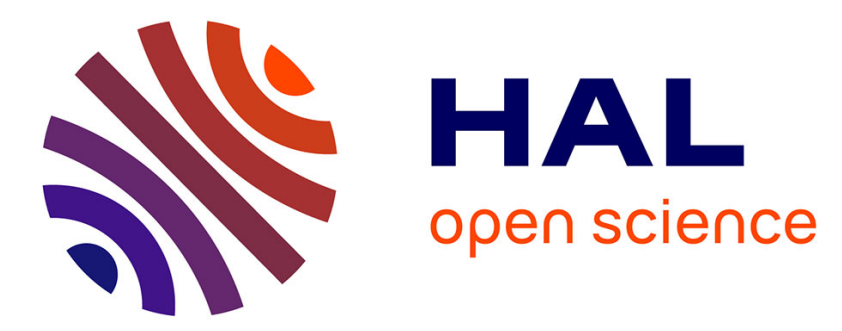

\title{
Mechanical properties, microstructure and crystallographic texture of magnesium AZ91-D alloy welded by Friction Stir Welding (FSW)
}

Afia Kouadri-Henni, Laurent Barrallier

\section{- To cite this version:}

Afia Kouadri-Henni, Laurent Barrallier. Mechanical properties, microstructure and crystallographic texture of magnesium AZ91-D alloy welded by Friction Stir Welding (FSW). Mechanical properties, microstructure and crystallographic texture of magnesium AZ91-D alloy welded by Friction Stir Welding (FSW), 2014, 45A (11), pp.4983-4996. hal-01175970

\author{
HAL Id: hal-01175970 \\ https://hal.science/hal-01175970
}

Submitted on 28 Aug 2015

HAL is a multi-disciplinary open access archive for the deposit and dissemination of scientific research documents, whether they are published or not. The documents may come from teaching and research institutions in France or abroad, or from public or private research centers.
L'archive ouverte pluridisciplinaire HAL, est destinée au dépôt et à la diffusion de documents scientifiques de niveau recherche, publiés ou non, émanant des établissements d'enseignement et de recherche français ou étrangers, des laboratoires publics ou privés. 


\section{Mechanical Properties, Microstructure and Crystallographic Texture of Magnesium AZ91-D Alloy Welded by Friction Stir Welding (FSW)}

\section{A. KOUADRI-HENNI and L. BARRALLIER}

The objective of the study was to characterize the properties of a magnesium alloy welded by friction stir welding. The results led to a better understanding of the relationship between this process and the microstructure and anisotropic properties of alloy materials. Welding principally leads to a large reduction in grain size in welded zones due to the phenomenon of dynamic recrystallization. The most remarkable observation was that crystallographic textures appeared from a base metal without texture in two zones: the thermo-mechanically affected and stirwelded zones. The latter zone has the peculiarity of possessing a marked texture with two components on the basal plane and the pyramidal plane. These characteristics disappeared in the thermo-mechanically affected zone (TMAZ), which had only one component following the basal plane. These modifications have been explained by the nature of the plastic deformation in these zones, which occurs at a moderate temperature in the TMAZ and high temperature in the SWZ.

\section{INTRODUCTION}

FRICTION stir welding (FSW) is a solid-state joining process that was invented by The Welding Institute (TWI), UK in 1991. ${ }^{[1]}$ The use of FSW is now more prevalent because it is rapid, precise, and easy to perform. ${ }^{[2]}$ It is increasingly being used in the shipbuilding, rail transport, automotive, small-component manufacturing, and aerospace industries. ${ }^{[2,3]}$ The greatest advantage of this method, however, is the ability to weld light structural materials, such as certain aluminum alloys and magnesium alloys that used to be considered unweldable or difficult to weld by conventional fusion-welding techniques. ${ }^{[4]}$ Indeed, this technique utilizes a rotating tool with a shoulder and a profiled probe that is plunged into work pieces and traversed along the weld centerline. ${ }^{[2,5]}$ No melting takes place during the process, thus maintaining relatively low temperatures and producing good-quality welds with significantly low residual stresses. ${ }^{[6]}$ The motion of the tool generates frictional heat within the work pieces, extruding the softened plasticized material around it and forging the same material in place so as to form a solid-state seamless joint. In this process, every parameter plays a particular role, which leads to several phenomena: the material undergoes intense shearing and dynamic recrystallization simultaneously.

A. KOUADRI-HENNI, Associate Professor, is with the PSM Team, European University of Brittany, France, INSA of Rennes, LGCGM, EA 3913, 20 Avenue des Buttes des Coesmes, 35708 Rennes, France. Contact e-mail: afia.kouadri-henni@insa-rennes.fr L. BARRALLIER, Professor, is with the MecaSurf Team, Arts et Métiers Paris Tech, France, ENSAM, Mecasurf, JE2504, 2 cours des arts, 13617 Aix en Provence, France.

Manuscript submitted April 10, 2013.

Article published online July 25, 2014
Several authors have confirmed this point and indicate that it is important to separate out the effect of final shoulder deformation through the forging action after the pin has passed. ${ }^{[7-10]}$ Indeed, the top layer undergoes shoulder deformation after the pin has passed through. This adds a shear deformation component at lower temperature to the recrystallized volume processed by the pin. ${ }^{[8]}$ In this process, the FSW material consists of four distinct microstructural zones: nugget or FSW, the thermo-mechanically affected zone (TMAZ), the heataffected zone (HAZ), and the base material (BM). Each zone has a different thermo-mechanical history. ${ }^{[9,10]}$ In addition, depending on the tool rotation rate and traverse speed, the nugget region can contain a ring pattern or other microstructural variations. ${ }^{[5,6,10,11]}$ What makes FSW even more complex is that the nugget region consists of sub-domains. The literature indicates that it is difficult to understand how the nucleation of new grains and continuous deformation influence the final texture. Indeed this FSW process leads to strong crystallographic texture. The deformation under the shoulder regions is likely to influence the final texture significantly. This point is fundamental because texture influences a variety of properties, including strength, ductility, formability, and corrosion resistance. ${ }^{[12,13]}$ A few texture studies regarding FSW aluminum and magnesium alloys have been reported. ${ }^{[14-16]}$ Sato et al. ${ }^{[17,18]}$ have reported a detailed texture analysis of FSW welds. The study of the texture evolution is required to understand the anisotropic characteristics of welds and their influence on mechanical properties. ${ }^{[19]}$ In our work, we chose to work with the magnesium alloy AZ91. The main interest in magnesium alloys lies in the fact that they are the lightest metallic materials currently available (magnesium density is about $\left.1.74 \mathrm{~g} / \mathrm{cm}^{3}\right)$. The use of magnesium alloy as a 
structural material is beneficial in reducing the weight of a vehicle. Thus, magnesium alloys possess excellent specific properties and are being designed to replace steel and aluminum in many structural applications. In general, they have about the same corrosion resistance as mild steel in similar environments but are less corrosion resistant than aluminum alloys. ${ }^{[20]}$ Moreover, magnesium alloys have limited strength, fatigue, and creep resistance at elevated temperatures as well as low stiffness and limited ductility. ${ }^{[20]}$ However, the formability of magnesium alloys is inferior to that of other metallic materials such as steel and aluminum alloys because of their hexagonal close-packed (HCP) structure, but it can be improved by grain refinement. ${ }^{[21,22]}$ For these reasons, magnesium alloys are still under development to improve their properties. With the increasing number of applications of magnesium alloys, a reliable joining process is required, but there are still a number of challenges associated with welding magnesium alloys. Indeed, magnesium alloys have been welded to repair structures because of the generation of many defects such as oxide films, cracks, and cavities. Therefore, the development of a suitable welding method for magnesium is an essential technology to make this material more widely applicable. However, conventional fusion techniques are difficult to use when joining thick sections of magnesium alloys. These techniques lead to poor surface properties, including low hardness, wear, and corrosion resistance, and they produce large shrinkage during solidification. ${ }^{[20,23]}$ Magnesium alloys can be joined using a wide variety of processes, but conventional processes have exhibited several disadvantages, such as a large HAZ, porosity, evaporative loss of the alloying elements, and high residual stresses. ${ }^{[23]}$ Thus, laser-beam welding and FSW are alternative methods that could overcome the abovementioned disadvantages. ${ }^{[23,24]}$

The objective of this study was to characterize the mechanical and microstructural property evolution in every zone of a welded sheet. This work characterized the microstructural modification (characterization of the grain size, chemical properties and phase analysis), the mechanical properties [yield strength (YS), ultimate tensile strength (UTS), elongation, and micro hardness) and the crystallographic texture occurring during FSW. The studied material was a magnesium alloy (AZ91) welded by FSW. The crystallographic texture was investigated using X-ray diffraction techniques.

\section{EXPERIMENTAL METHODS}

\section{A. Sample Presentation}

The alloy used in the study of FSW welding was a ternary magnesium-aluminum-zinc alloy with the designation AZ91 according ASTM standards. The chemical composition of the BM is presented in the Table I. Sheets of AZ91 alloy presented in Figure 1 were obtained from an industrial source (Messnier Foundries). They were obtained by high-pressure die casting under neutral gas and did not undergo heat treatment to maintain the as-cast condition, which is generally used
Table I. Chemical Composition of AZ91 Alloy in Base Metal, BM, (EDS Analysis) ${ }^{[25]}$

\begin{tabular}{lrccc}
\hline $\begin{array}{l}\text { Chemical Composition } \\
\text { (Weight Percent) }\end{array}$ & $\mathrm{Al}$ & $\mathrm{Mg}$ & $\mathrm{Zn}$ & $\mathrm{Mn}$ \\
\hline Base metal & & & & \\
$\quad$ Matrix $\alpha(\alpha+\beta)$ & 32.5 & 90.6 & 1.15 & 0.15 \\
Precipitates $\beta$ & 32.8 & 14.5 & - & - \\
Precipitates $\mathrm{Al}_{8} \mathrm{Mn}_{3}$ & - & 52.7 \\
\hline
\end{tabular}

in automobile applications. The plates obtained were sheared to recover the areas measuring $3 \mathrm{~mm}$ in thickness. Their edges were machined by milling. For the experimental study performed within the framework of our research, we machined samples into parallelepidic shapes with dimensions of $300 \times 100 \times 3 \mathrm{~mm}^{3}$. The tensile strength of the $\mathrm{BM}$ was $230 \mathrm{MPa}$.

\section{B. Parameters of Welding Proceeding}

\section{Methodology}

Two plates were welded together side by side using a FSW process. FSW processing was carried out with machines located at the Welding Institute (IW-GESAB). To validate the optimization strategy, a plan of experiments has been carried out following a simplified plan of Tagushi. A pin diameter of $5 \mathrm{~mm}$ and shoulder of $10 \mathrm{~mm}$ have been used. The process parameters that were varied were the welding speed $(V)$ and tool rotation rate $(W)$. The optimized domains are summarized in Table II. Experiments performed showed that increasing welding speed $(V)$ at a constant tool rotation rate $(W)$ was resulting in inside voids and lack of bonding caused by the insufficient material flow. For a constant welding speed, a low tool rotation rate was leading to the formation of inner voids because the frictional heat was not sufficient to promote material flow. These defects disappeared with increasing $W$, but with a further increase, inner voids, lack of bonding, and surface crack due to excess expelling of the material are created. Different clamping systems and different welding pressures were tested. The welding can be performed using either a position control mode (i.e., the tool was advanced at a constant height and the vertical pressure was adjusted) or load control mode (i.e., the tool was advanced at a constant vertical pressure and the tool height was adjusted). In our study, we have used the load control mode (Table III). The penetration depth was adapted to a fully penetrated butt joint in a material measuring $3 \mathrm{~mm}$ in thickness. After welding, the welded samples have dimensions of $300 \times 200 \times 3 \mathrm{~mm}^{3}$ (Figure 1$)$.

\section{Optimized welding conditions}

From microstructure variation point of view, results showed that a low welding speed could provide a controlled dynamic recrystallization leading to a fine grains structure. We observed that increasing of this ratio was leading to an increase in the heat input, an improved material flow and then, a wider and deeper weld nugget. From mechanical properties point of view, 


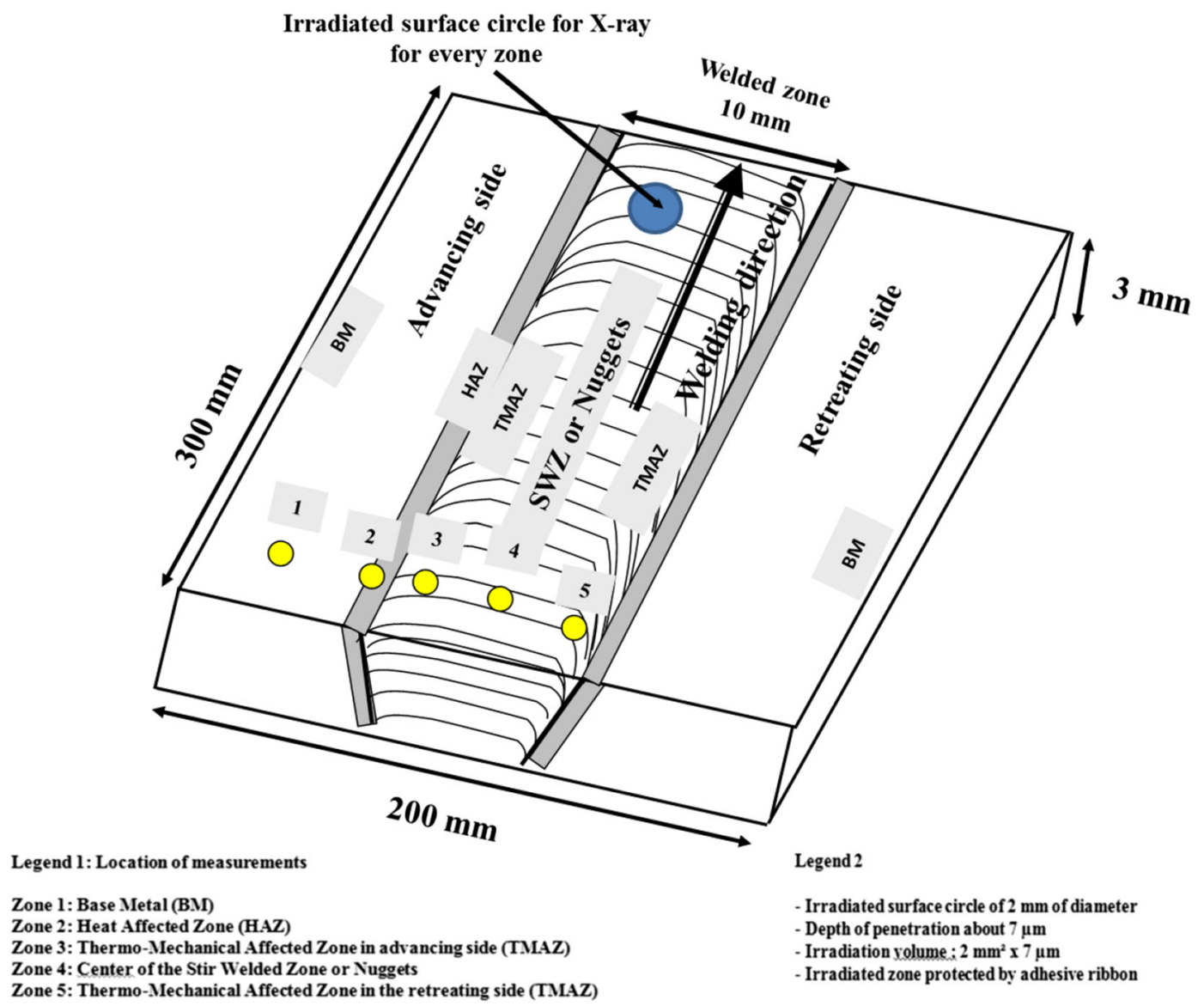

Fig. 1-Geometric dimensions of the material and locations of the measurement.

Table II. Selected Parameters

\begin{tabular}{llll}
\hline $\begin{array}{l}\text { Facility: IW-G-ESAB } \\
\begin{array}{l}\text { Welding speed } W \\
(\mathrm{~mm} / \mathrm{min})\end{array}\end{array}$ & $<80$ & 80 to 200 & 80 to 200 \\
$\begin{array}{l}\text { Tool rotation rate } W \\
(\mathrm{RPM})\end{array}$ & 100 & 200 to 1000 & 1000 to 1400 \\
$\begin{array}{l}\text { Observations } \\
\text { voids }\end{array}$ & voids + cracks & sound welds \\
\hline
\end{tabular}

Table III. Welding Pressure Selected

\begin{tabular}{lcl}
\hline $\begin{array}{l}\text { Welding Pression } \\
(\mathrm{kN})\end{array}$ & $\begin{array}{c}\text { Welding Speed } V \\
(\mathrm{~mm} / \mathrm{min})\end{array}$ & Observations \\
\hline 0.5 & 90 & voids + cracks \\
1 & 90 & voids + cracks \\
1.5 & 90 & sound welds \\
\hline
\end{tabular}

results showed that the increasing welding speeds over a critical value lead to decrease the UTS while the YS was kept constant. With a further increase in welding speed, the weld tensile strength dropped, that was attributed to the appearance of many defects: porosity, cracks, and lack of clash between the two plates. These observations are consistent with all the studies carried out previously in the literature..$^{[3,10,26]}$ In conclusion, many parameters
Table IV. Welding Parameters Choice

\begin{tabular}{lcc}
\hline $\begin{array}{l}\text { Welding } \\
\text { Pression }(\mathrm{kN})\end{array}$ & $\begin{array}{c}\text { Welding Speed } V \\
(\mathrm{~mm} / \mathrm{min})\end{array}$ & $\begin{array}{c}\text { Tool Rotation } \\
\text { Rate } W(\mathrm{rpm})\end{array}$ \\
\hline 1.5 & 90 & 1200 \\
\hline
\end{tabular}

can be considered in FSW. In our case the following parameters have been retained and summarized in the Table IV.

\section{Metallurgical Analysis}

1. Grains size measurement by microscopy optical

The aim of this part is to have a detailed description of the microstructural properties (distribution of the grains size) in every studied zone. The microsections for the structure examination were first polished with sandpaper of 450 to 1200 grits and then mechanically polished with 3 and $1 \mu \mathrm{m}$ diamond oil-suspension. After mechanical polishing to a mirror finish, the welds were examined by optical microscope. The microstructure of the magnesium alloy was exposed by Nital Etchant (20 pct $\mathrm{HNO}_{3}, \mathrm{C}_{2} \mathrm{H}_{5} \mathrm{OH}$ ) and by the reaction of Keller Etchant $\left(2.5 \mathrm{~mL}\right.$ of $\mathrm{HNO}_{3}, 1.5 \mathrm{~mL}$ of $\mathrm{HCl}, 1.0 \mathrm{ml}$ of $\mathrm{HF}$, and $95 \mathrm{~mL}$ of water). ${ }^{[25]}$ Observations were also made using a scanning electron microscope (SEM); 
point chemical analysis was carried out on the samples using an electron microprobe (EDS).

\section{Image analysis procedure}

The distribution of the grains size presents in the base metal (BM) and in the melted zone were obtained by image analysis from several microstructures studied by optical microscopy. The analysis of the image was done using a camera combined with an optical microscope. The images were analyzed using the Image $\mathbf{J}$ software, which allows for surfaces to be defined and grains to be counted and grouped into diameter groupings. The distribution of the grains size was obtained via the method of grain counting per unit area $(\mathrm{Np})$ in different $2 \mathrm{D}$ sections obtained from the optical microscopy. Because the material had a heterogeneous distribution, we used the iterative method which uses the distribution of the diameters of the circles obtained. ${ }^{[27]} \mathrm{We}$ used different classes to distinguish the different phases present. By counting the number of grains we drawed the distribution of the different grains classes by using the Fridy et al. ${ }^{[28]}$ ratio which states that the volume fraction is equal to the ratio of surface cuts: $V_{\mathrm{v}}=A_{\mathrm{a}}$.

\section{Phase analysis and crystallographic texture}

X-ray diffraction analysis was used to identify nature of the phases and to evaluate the crystallographic texture of the samples. Matter removal by chemical means was necessary in order to measure the crystallography texture at an interior point of a solid by means of X-ray diffraction. We performed an electrochemical polishing. A $5 \mathrm{~mm}$ diameter disks were electrochemically polished in a Struers Tenupol-3 jet polisher at a temperature below $283 \mathrm{~K}\left(10^{\circ} \mathrm{C}\right)$ with a $14 \mathrm{~V}$ polishing voltage. The polishing solution was 10 pct $\mathrm{HCl}, 90$ pct $\mathrm{C}_{4} \mathrm{H}_{9} \mathrm{OCH}_{2} \mathrm{CH}_{2} \mathrm{OH}$ (butoxy-2-ethanol) by volume. Material removal was performed by applying a voltage and shooting a jet of an electrolyte at a side of the sample. Large areas of the sample were then thinned without introducing any mechanical damage. The process stopped automatically when a hole is made in the specimen. Checks of depths were performed using a comparator in order to confirm the depth of polishing. From a crystallographic point of view, the following areas were probed by X-ray diffraction measurements taken close to the surface (Figure 1): into the base metal (BM, zone 1), in the heat-affected zone (HAZ, zone 2), in the thermo-mechanical zone (TMAZ, zone 3 and 5), respectively, in the advancing side (AS) and in the retreating side (RS) and in the stir-welded zone (SWZ, zone 4), which is also called the nugget zone (NZ). The friction welded zone (FSW) contains the two zones: the TMAZ and the SWZ. The diffractometer is equipped with a four-circle goniometer (Seifert MZ VI-TS). The X-ray source has a $1 \mathrm{~mm}$ point collimator and the goniometer is equipped with a position sensitive detector (PSD). $\mathrm{Cr} \mathrm{K} \mathrm{K}_{\alpha}$ radiation was used to perform the phase and the texture analysis. Generator current and voltage levels used were $30 \mathrm{~mA}$ and $40 \mathrm{kV}$. The irradiated zone was limited by a mask represented by a circle of $2 \mathrm{~mm}$ diameter (Figure 1). Under these conditions the depth to which the alloy is penetrated is estimated at $7 \mu \mathrm{m}$ and the surface examined by X-ray diffraction was about $2 \mathrm{~mm}^{2}$ in area. A complete description of the texture in a hexagonal structure requires five pole figures. The pole figures were obtained from the Bragg peaks of the main $\alpha$-magnesium phase (hexagonal structure). The pole figures corresponding to the following planes were measured: $\{10 \overline{1} 0\}$ prismatic plane, $\{0002\}$ basal plane, $\{10 \overline{1} 1\}$ pyramidal plane, $\{10 \overline{1} 2\}$ first-order pyramidal plane, and $\{11 \overline{2} 0\}$ prismatic plane. The intensity is expressed as the number of counts per second (cps). The corresponding time of measurement was 4 hours per pole figure. The data were obtained as a function of the tilt $\Psi$ angle (polar angle), which ranged from 0 to $70 \mathrm{deg}$ from the axial direction of the sample in steps of $5 \mathrm{deg}$, and the azimuthal angle ( $\phi$ angle), which ranged from 0 to $360 \mathrm{deg}$ in steps of $10 \mathrm{deg}$ from the reference direction in the plane of the sample. Pole figures were plotted using a standard stereographic projection, with the welding axis $(Z)$ and the longitudinal reference direction aligned along the North Pole. The reference system selected featured a $Z$-axis normal to the plates (ND: normal direction). The $X$ and $Y$ directions were on the plane parallel to the metal and corresponded to the longitudinal direction (LD) and transverse direction (TD), respectively. The orientation distribution function (ODF) was calculated from five complete pole figures, using a discrete method arbitrarily defined cells method (ADC). ${ }^{[25-27]}$ The complete pole figures were calculated using Labotex software. The volume fraction of each component, $g$, has been calculated by integration around each orientation in the ranges given by chosen set of texture components and for each Euler angle. The chosen orientations have been entered in form Euler angles: $\varphi_{1}=205 \mathrm{deg}, \Phi=55 \mathrm{deg}, \varphi_{2}=12.5 \mathrm{deg}$ for the $\{0002\}\langle 21 \overline{3} 0\rangle$ orientation and $\varphi_{1}=165 \mathrm{deg}, \Phi=55$ deg, $\varphi_{2}=28 \mathrm{deg}$ for the $\{10 \overline{1} 1\}\langle 11 \overline{2} 0\rangle$ orientation.

\section{Mechanical Analysis}

\section{Hardness measurement}

The microhardness was measured by a Vickers indenter under a load of $100 \mathrm{~g}$ on cross sections applied for 15 seconds. A program on a conventional optical microscopy measured the diagonal lines of the mark. Two measurement series have been realized, one close to the surface from the FWZ until the BM in every location and the other with the same profile at a depth around $200 \mu \mathrm{m}$ in every location. Microhardness samples were made from 3-mm-thick plates. The same procedure has been used that optical measurement to remove a thickness approximately around 180 to $200 \mu \mathrm{m}$. Checks of removed depth were performed using a comparator in order to confirm the depth of polishing of $200 \mu \mathrm{m}$.

\section{Tensile tests}

Dumbell specimen preparation was performed using water jet cutting. We cut the welded plates transversely across the weld. The lateral section was then polished to avoid crack initiation during tensile test. An Instron machine with mechanical grips and a $50 \mathrm{kN}$ load cell was used and tensile tests were performed at $5 \mathrm{~mm} / \mathrm{min}$ 
strain rate. A sketch of dumbell specimen dimension is exhibited in Figure 2.

\section{RESULTS AND DISCUSSION}

\section{A. Macrostructure Characterizations of the Welded Zones}

1. Macrostructure on the top of the welded surface

Figure 3 shows the macrostructure of a cross section in a friction stir weld obtained at a rotation speed $1200 \mathrm{rpm}$, a travel speed of $90 \mathrm{~mm} / \mathrm{min}$, and a welding pressure of $150 \mathrm{~N}$.

We produced the generalized profile of a butt joint in the form of an inverted trapezoid exhibiting several zones. Macrostructural studies revealed the formation of four different areas: the BM, the HAZ, the TMAZ, and the SWZ. Our results are in agreements with the results of the literature which confirms the fact that this process leads to four zones where each zone corresponds to various changes in microstructure. ${ }^{[1,2]}$ Moreover, we

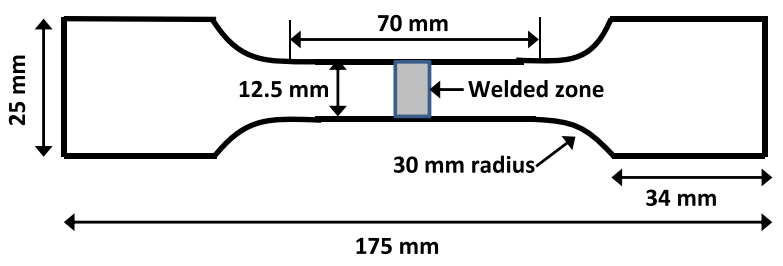

Fig. 2- Geometric dimensions of the dumbbell specimen for the tensile tests. observed that the width of the FWZ of the experimental material was about $10 \mathrm{~mm}$, equal to the diameter of the shoulder used during the welding. In the NZ, the macrostructure shows that the flow field of the friction stir welds runs along the retreating and AS (Figure 3). This is explained in the literature by the fact that the tool advance vector is in line with the tangent vector of a shoulder fringe called the AS; the opposing vector is called the RS. ${ }^{[29,30]}$

\section{Macrostructure on the weld sides}

Figure 4 shows the macrostructure of a cross section of a friction stir weld on both weld sides (advancing and RSs). This macrostructure shows shear bands. These band features were identified in each butt weld produced and also in the bead-on-plate welds. We can see that the bands generally cut straight through the material, but branching has also been observed. Several bands were observed on the sample edges. Sample preparation prior to welding was performed by milling the sample edges. After the milling process, the edges did not show any shear bands. Thus, in our case, we can confirm that the welding process causes these features. These bands are called adiabatic shear bands in the literature. ${ }^{[31]}$

\section{B. Distribution of Grains Size of Phases by Image Analysis}

Before analyzing the microstructure modification, we realized a statistical distribution of the different grain sizes in the different studied zones. In the BM, the mean grain sizes range from 50 to $250 \mu \mathrm{m}$ (Figure 5(a)). This

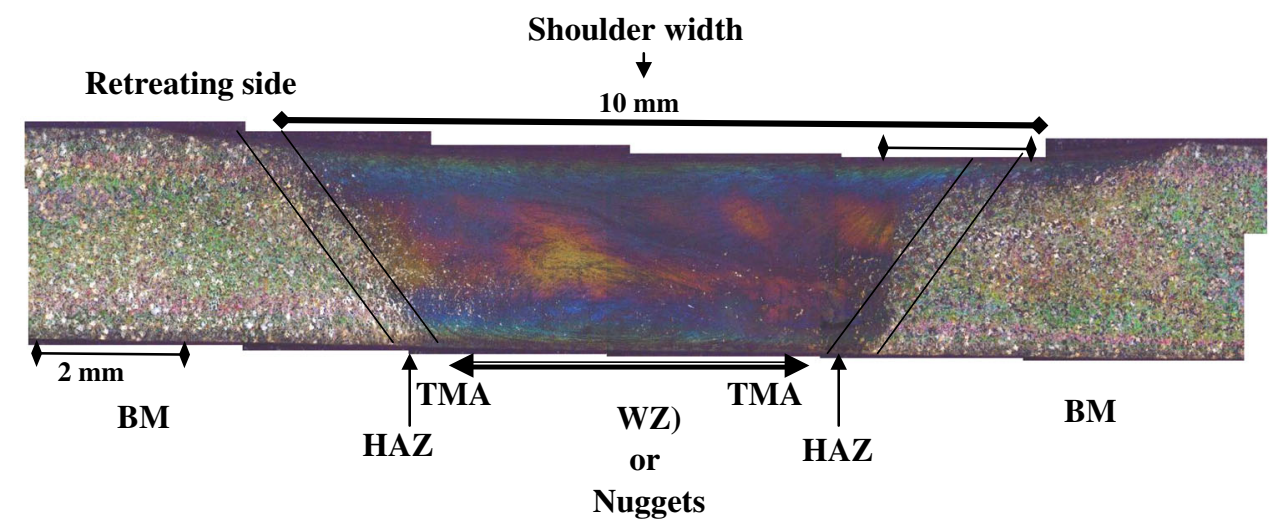

Fig. 3-Macrostructure of FSW cross-section showing the different microstructural zones.

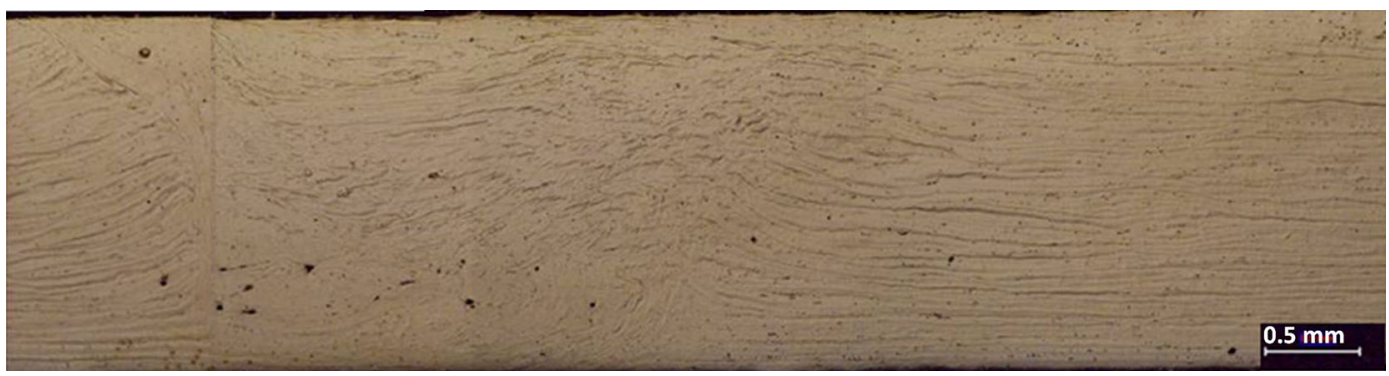

Fig. 4-Macrostructure of FSW cross-section showing shear bands on both weld sides. 


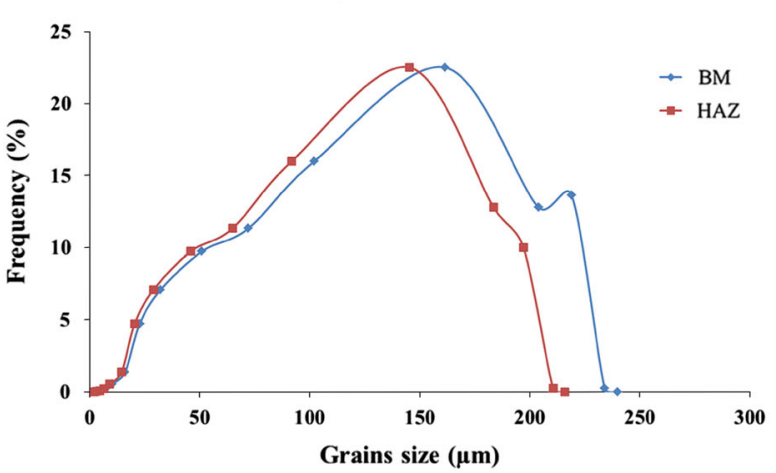

(a)

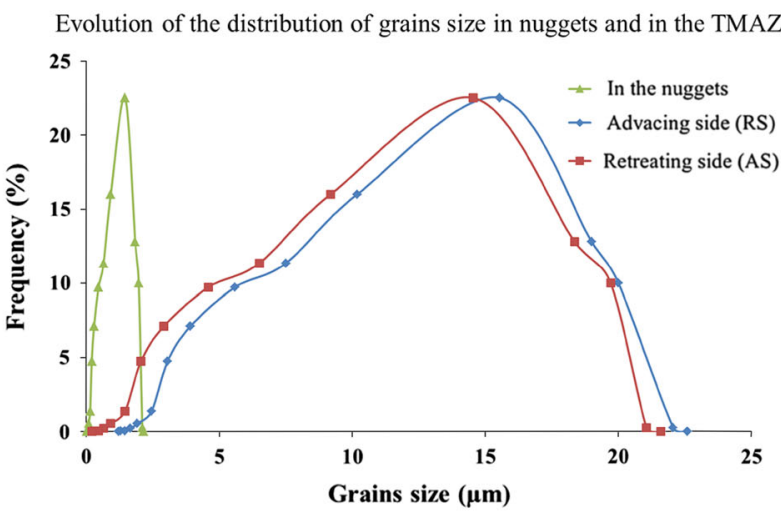

(b)

Fig. 5-Distribution of the grains size $(a)$ in the base metal (BM) and HAZ, $(b)$ in the nuggets and in the TMAZ zones (RS, AS).

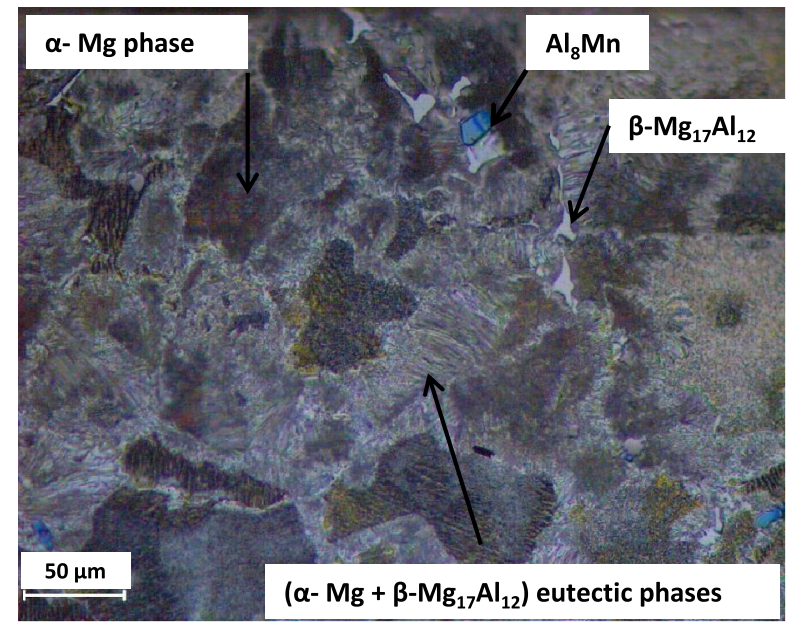

(a)

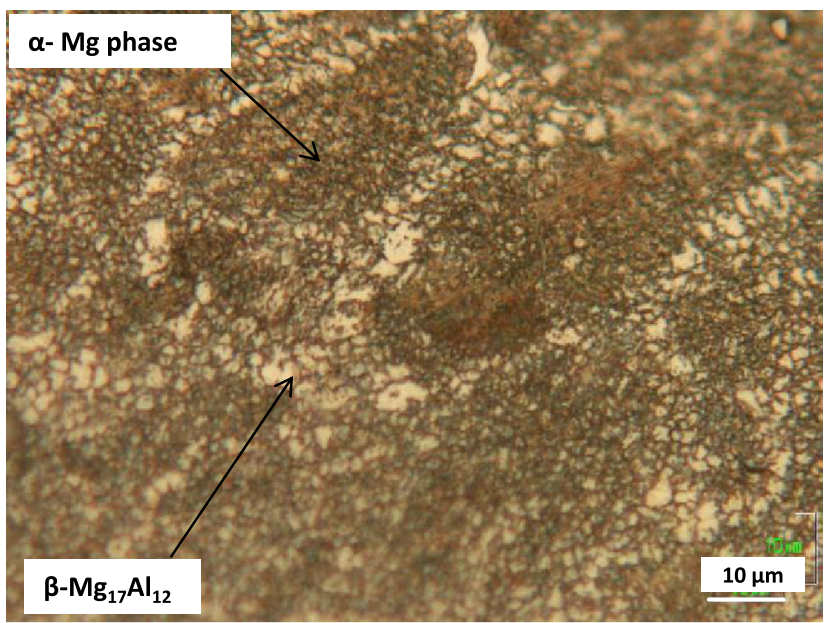

(b)

Fig. 6-(a) Microstructure of the base metal (BM). (b) Microstructure of the heat-affected zone (HAZ).

distribution shows that the principal mode located about $160 \mu \mathrm{m}$. These results are in line with those in the literature and the diagram of the alloy phase AZ91. ${ }^{[18]}$ A little reduction of grains in the HAZ is confirmed in the Figure 5(a). The principal mode in this zone is about $140 \mu \mathrm{m}$. Some grains present a grains size near that of the BM (Figure 5(a)). The large reduction of grains in the welded zone is confirmed by statistical distribution of the grains (Figure 5(b)) where the principal mode is about 16 and $14 \mu \mathrm{m}$ in the TMAZ, respectively, in AS and $\mathrm{RS}$ and $2 \mu \mathrm{m}$ in the nuggets zone.

\section{Microstructures in the Four Zones}

\section{Base metal (BM) and $H A Z$}

The microstructure of the BM used in this study is mainly composed of a mixture of a granular phase of magnesium solid-solution grains and of $(\alpha-\mathrm{Mg}+$ $\left.\beta-\mathrm{Mg}_{17} \mathrm{Al}_{12}\right)$ eutectic phases, which are indicated by arrows in Figure 6(a). This latter constituent is called an abnormal eutectic ${ }^{[4,32]}$ because of its lamellar shape. The BM exhibits very small precipitates dispersed in the matrix, which are mainly located at the grain boundaries. These precipitates are composed of $\beta-\mathrm{Mg}_{17} \mathrm{Al}_{12}$ and, to a lesser degree, $\mathrm{Al}_{8} \mathrm{Mn}_{3}$. In the FSW process, the $\mathrm{HAZ}$, is a zone where the material experiences no plastic deformation. The metal was neither stirred by the pin nor rubbed by the shoulder but was influenced by the heat of welding, leading to some microstructural changes. ${ }^{[29,30]}$ Our results show a microstructure close to that of the BM, though some differences between the $\mathrm{BM}$ and the HAZ have been observed. The eutectic phase $\left(\alpha-\mathrm{Mg}+\beta-\mathrm{Mg}_{17} \mathrm{Al}_{12}\right)$ was dissoluted by $\alpha-\mathrm{Mg}$ grains in the matrix and the $\beta-\mathrm{Mg}_{17} \mathrm{Al}_{12}$ phase was arranged along the grain boundaries (Figure 6(b), indicated by arrows). This modification confirmed the ongoing process of dissolution due to the heat conduction. Therefore, this phenomenon explains that the grains are smaller compared the BM (Figure 5(a)). But we sometimes observed crystal grains that grew in the HAZ and have a size near than those in the BM. These observations are confirmed in the literature. ${ }^{[33,34]}$ 


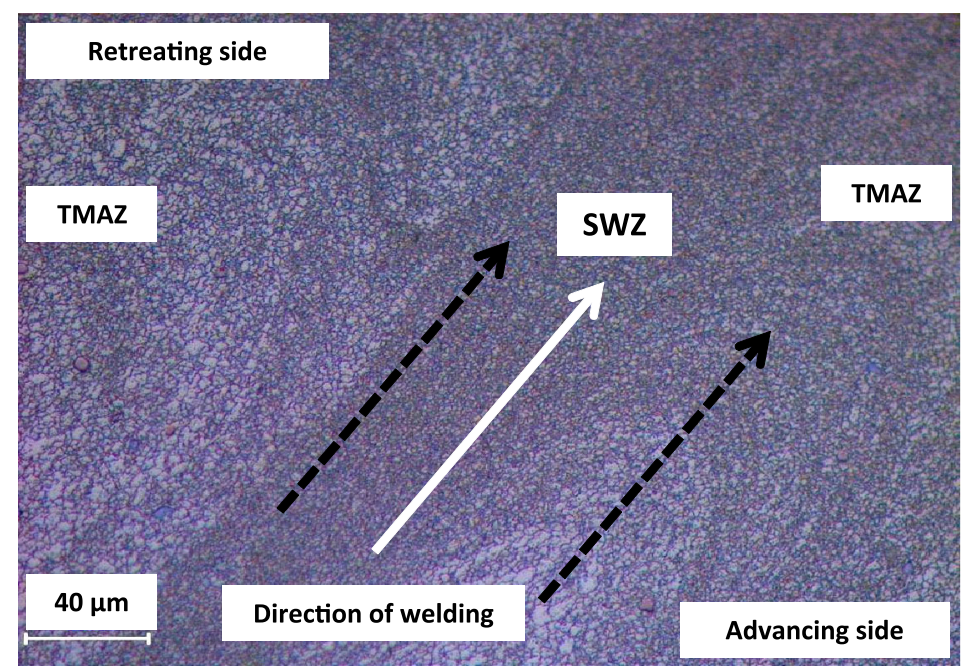

(a)

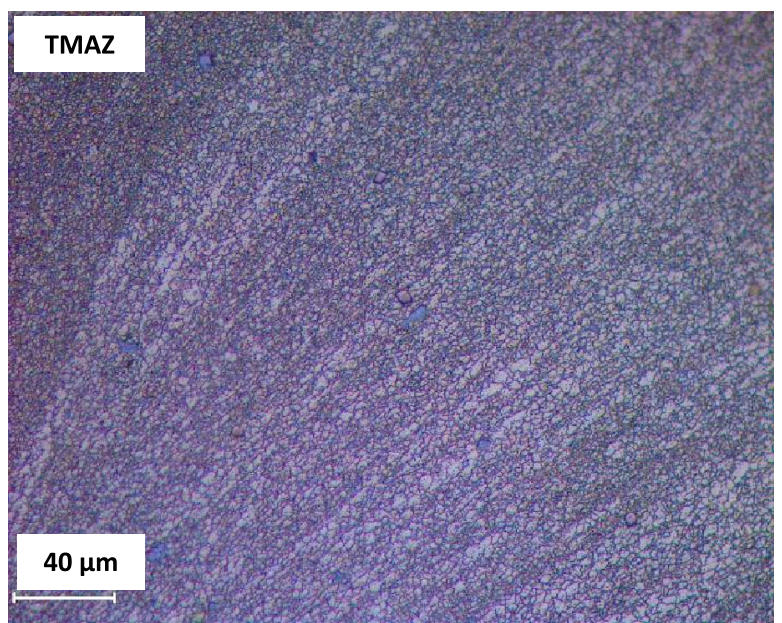

(b)

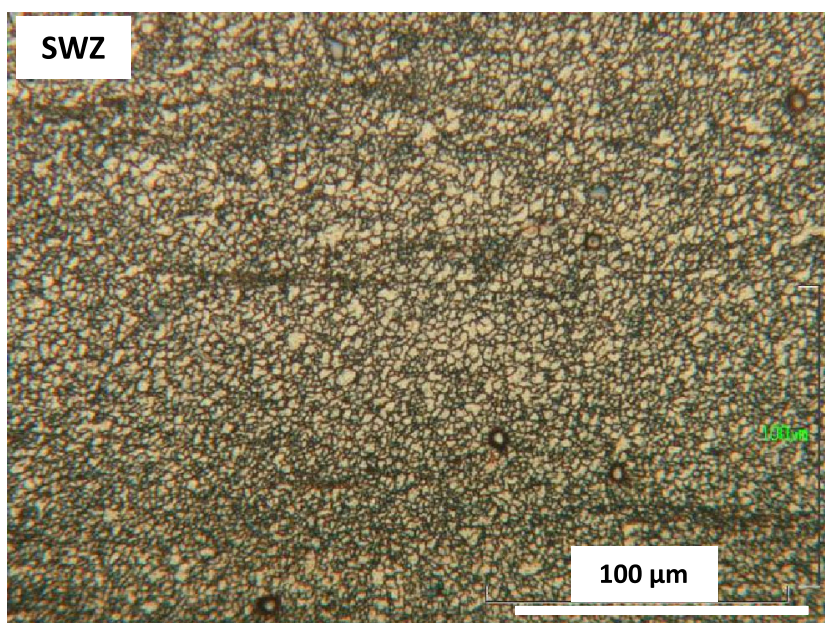

(c)

Fig. 7-(a) Microstructure of the welded zone. (b) Microstructure in the thermo-mechanical affected zone (TMAZ). (c) Microstructure in the stir-welded zone (SWZ) or nuggets.

\section{Welded structure}

The welded zone is composed of two parts: the transition region (TMAZ) and the SWZ. These zones underwent grain refinement (Figures 5(b) and 7), which produced grains that were significantly smaller than those in the BM and the HAZ regions. Two different grain sizes were observed in the following zones (Figure 5(b)): in the hole corresponding to the pin location (i.e., in the SWZ) and the fine-grained area observed under the shoulder (i.e., in the TMAZ). However, these two zones are also characterized by significant differences.

a. The TMAZ and interface TMAZ/FSW. In the TMAZ (Figures 7(a) and (b)), magnesium grains presented an elongated shape due to plastic deformation during FSW. We observed that a deformed grain structure consisting of subgrains is formed just outside the stir zone in the TMAZ. The deformation of the grains increased with decreasing distance from the SWZ. Under the shoulder, some very fine-grained lines following the tool rotation were observed (Figure 7(a)).
These were formed of several lines following the tool rotation and alternating small and large grains. The microstructure consists of partially recrystallized grains. The result is that the grain size in the TMAZ is coarser than that in the nugget region, following a grain size gradient, because of insufficient deformation and thermal exposure (Figure 5(b)). These observations are confirmed by the distribution of grains size (Figure 5(b)). Moreover, our results show that there is a little variation in grain size (Figure 5(b)) in the RS (14 $\mu \mathrm{m})$ compared to that in the AS $(16 \mu \mathrm{m})$, which is caused by the greater straining expected in the latter location. These results have been explained by the fact that this zone undergoes only plastic deformation in the retreating and in the AS of the nugget at relatively low temperature. This phenomenon is caused by an insufficient heating temperature and a strong inhomogeneity in strain deformation, which leads to partial dynamic recrystallization during FSW. Similar observations were made by several authors during the FSW of AZ31B magnesium alloy. ${ }^{[30,33,35-38]}$ 
b. Stir-welded zone (SWZ) or nuggets zone (NZ). In the SWZ (Figures 7(b), (c)), the microstructure consists almost entirely of dynamically recrystallized magnesium grains and intermetallic compounds tend to disappear due to dissolution at elevated temperature. The grain refinement is clearly visible under the tool, (i.e., in the $\mathrm{NZ}$ ) and the grain size is homogeneously centered on 2 $\mu \mathrm{m}$ (Figure 5b). Grain refinement ahead of the tool is primarily caused by plastic spin and rigid rotations associated with shear deformation processes rather than by dynamic recrystallization. These observations are in agreement with those reported in the literature that state that during the FSW process the material undergoes intense plastic deformation at elevated temperature, resulting in the generation of fine and equiaxed recrystallized grains. ${ }^{[2,3,10,39]}$ These equiaxed grains are formed through the process of dynamic recrystallization during FSW. ${ }^{29,30,33,34,39,40]}$ By carefully examining our microstructure of the SWZ, some narrow bands of particles can be observed, indicating material flow patterns (Figure 7(c)), which seems indicating the presence of twinning.

\section{Phases Analysis by X-ray Diffraction}

\section{In the $B M$ and in the $H A Z$}

Figure 8(a) shows the diffraction patterns measured in the BM. In this zone, the predominance of the $\alpha-\mathrm{Mg}$ phase is confirmed by X-ray analysis. Peaks corresponding to $\beta-\mathrm{Mg}_{17} \mathrm{Al}_{12}$ also appear but at a lower intensity. Finally, a third class of peaks is observed, which corresponds to the superposition of the two phases $\alpha$ and $\beta$ (for example $2 \theta=117 \mathrm{deg}$ ). In the HAZ (Figure 8(b)), there is no significant difference in the peak positions between these two zones. The principal modification observed in this zone close to the surface is the change in the height of the peaks.

\section{In the TMAZ and in the FSW ( $A S$ and $R S$ )}

Figures 8(c) through 8(e), which show the X-ray diffraction results in the TMAZ and SWZ zones, reveal variations in the peak intensities with respect to the BM. We can see a decreasing in the peak heights compared to those of the BM. There is no longer a $(\alpha+\beta)$ eutectic phase, or perhaps the volume fraction is very small in these zones. These results have been explained by the dissolution of this phase during FSW processing in these welded zones. These observations confirmed those of microstructure evolution. The literature suggests that sufficient frictional heating introduced during the stirring period of FSW leads to microstructures not containing a eutectic structure in the transition region and the stir zone (i.e., both of these regions are probably heated at temperatures higher than $593 \mathrm{~K}\left(320^{\circ} \mathrm{C}\right)$ during FSW). Indeed, the $\mathrm{Al}-\mathrm{Mg}$ phase diagram ${ }^{[4,20]}$ shows that a heating temperature above about $593 \mathrm{~K}$ $\left(320^{\circ} \mathrm{C}\right)$ causes the dissolution of the eutectic phases by $\mathrm{Al}_{12} \mathrm{Mg}_{17}$ phases in the grains boundary and $\alpha$-phase into the magnesium matrix.

The difference between the TMAZ (Figures 8(c) and (d)) and the SWZ (Figure 8(e)) can be observed by the variation in the heights of the peaks. These reduced intensities can provide information regarding the presence of texture and quantitative insights into the variation of the texture in the different zones. We will confirm this point with a comparison of the full pole figures. These modifications can be explained by the presence of a texture that may be responsible for this decrease (in the TMAZ) or for this increase in the SWZ. This is the reason why no quantitative analysis should be performed without first performing a textural analysis. Moreover, the diffraction pattern of the welded zone measured at the surface shows an increase in the (0002) peak intensity, which may be attributed to the variation in the recrystallized texture.

\section{E. Texture Characterization}

Superficial texture analysis was performed using laboratory XRD. Measurements were made in the nugget, TMAZ, HAZ, and BM. The pole figures were examined with respect to the surface and central regions on both sides of the centerline (i.e., on the advancing and RSs). With respect to the anisotropic properties of the materials considered, the evaluation of the crystallographic texture indicates that FSW induces particular profiles in the studied zones. In our case, the BM was molded and it did not exhibit any texture. The HAZ also did not exhibit any texture.

\section{Base metal and $H A Z$}

By examining the intensity values of the pole figures (Figure 9(a)), the texture of the BM can be characterized by concentrated, strong reflections. These results should be interpreted with a certain degree of reservation because in the BM the grain size is large (50 to $250 \mu \mathrm{m}$ ). The irradiated volume is not representative of all sheets. To define all orientations, it would be necessary to explore a greater volume of matter. Concerning the HAZ, the results permit to show a random texture compared to that of the BM (Figure 9(b)). These results are reasonable because the HAZ grains decrease slightly compared to the parent material. Indeed, this zone does not undergo any plastic deformation but experiences thermal cycling. This temperature leads to some microstructural change but is not sufficient to modify the crystallographic texture of this zone.

\section{Welded zones}

Our results confirm the formation of texture in the welded zones by FSW processing (Figure 10). Because the parent metal does not exhibit any texture, the textures existing in the welded zones are caused only by FSW processing. These zones were deformed and influenced by heat. By examining the intensity values in the stirred zone (nugget), (Figure 10(a)), we could observe that this zone is characterized by several concentrated and strong reflections. The ODF calculation indicates two preferential orientations of the grains with the $\{0002\}\langle 21 \overline{3} 0\rangle$ texture (34 pct) and $\{10 \overline{1} 1\}\langle 11 \overline{2} 0\rangle$ (36 pct) texture, which correspond to the three Euler angles $\left(\varphi_{1}=205 \mathrm{deg}, \Phi=55 \mathrm{deg}\right.$, $\left.\varphi_{2}=12.5 \mathrm{deg}\right)$ and $\left(\varphi_{1}=165 \mathrm{deg}, \quad \Phi=55 \mathrm{deg}\right.$, $\varphi_{2}=28 \mathrm{deg}$ ), respectively. In this zone, our results 


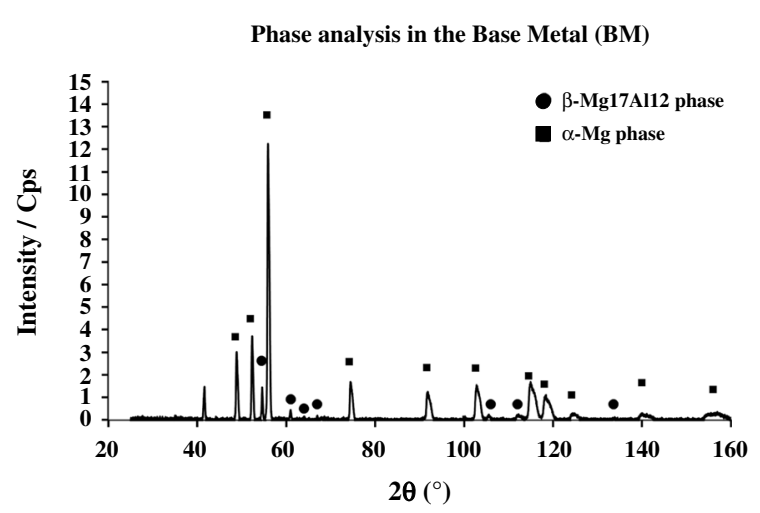

(a)

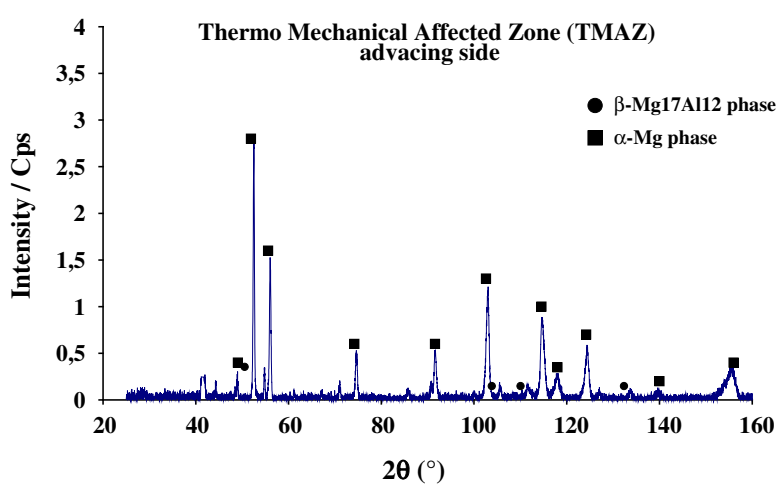

(c)

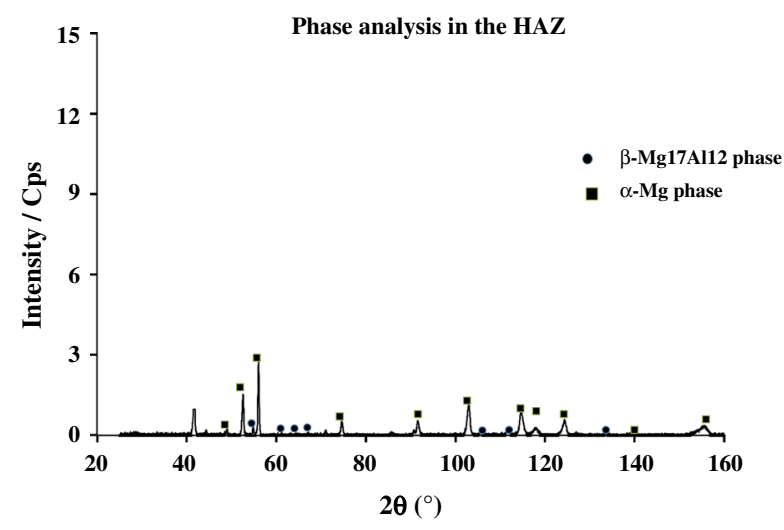

(b)

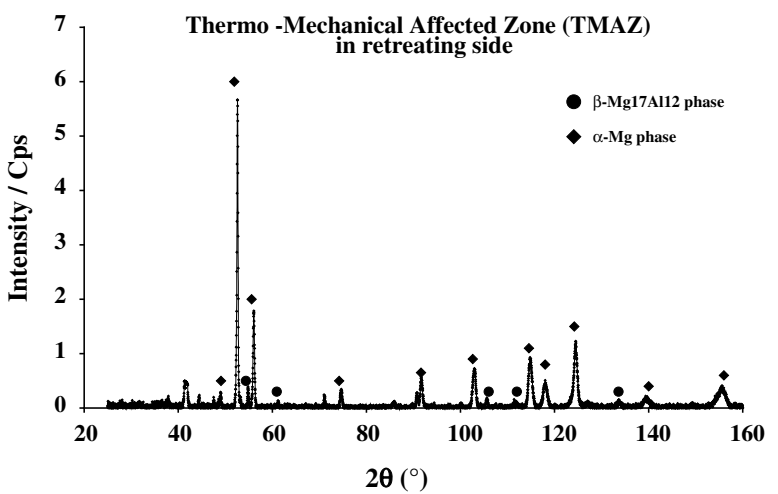

(d)

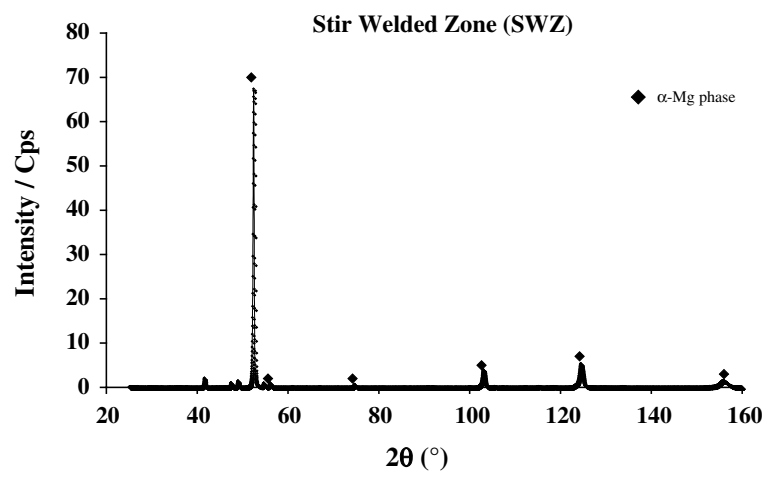

(e)

Fig. 8- (a) X-ray diffractogram of AZ91 alloys in BM. The peaks with the indices are the reflections corresponding to $\alpha$-Mg solid solution to $\beta$ - $\mathrm{Mg}_{17} \mathrm{Al}_{12}$ precipitates. (b) X-ray diffractogram of AZ91 alloys in HAZ. The peaks with the indices are the reflections corresponding to $\alpha$-Mg solid solution to $\beta$ - $\mathrm{Mg}_{17} \mathrm{Al}_{12}$ precipitates. (c) X-ray diffractogram of AZ91 alloys in the TMAZ in the advancing side. The peaks with the indices are the reflections corresponding to $\alpha-\mathrm{Mg}$ solid solution to $\beta-\mathrm{Mg}_{17} \mathrm{Al}_{12}$ precipitates. (d) X-ray diffractogram of AZ91 alloys in the TMAZ in the retreating side. The peaks with the indices are the reflections corresponding to $\alpha-\mathrm{Mg}$ solid solution to $\beta$ - $\mathrm{Mg}_{17} \mathrm{Al}_{12}$ precipitates. (e) X-ray diffractogram of AZ91 alloys in SWZ. The peaks with the indices are the reflections corresponding to $\alpha$-Mg solid solution.

show that the grain $\{0002\}$ basal plane normal is aligned to the welding direction by FSW. The (0002) planes tended to align along an ellipsoidal surface in the nugget-shaped stir zone. The basal plane normal followed the shoulder rotation and aligned with the welding direction in the weld center. These observations are in agreement with those made by authors who reported that in the as-welded condition the SWZs are principally characterized by the presence of a texture with the
$\{0002\}$ basal plane normal parallel to the ND, which is the typical friction texture of magnesium alloys. ${ }^{[12,14,41-43]}$ On the other hand, in this zone, the appearance of another texture component in the SWZ $\{10 \overline{1} 1\}$ in addition to that of the basal plane indicates that FSW leads to different mechanisms in the stirred zone: during FSW, the material undergoes intense shearing and dynamic recrystallization concurrently due to an elevated temperature. According to the literature, 

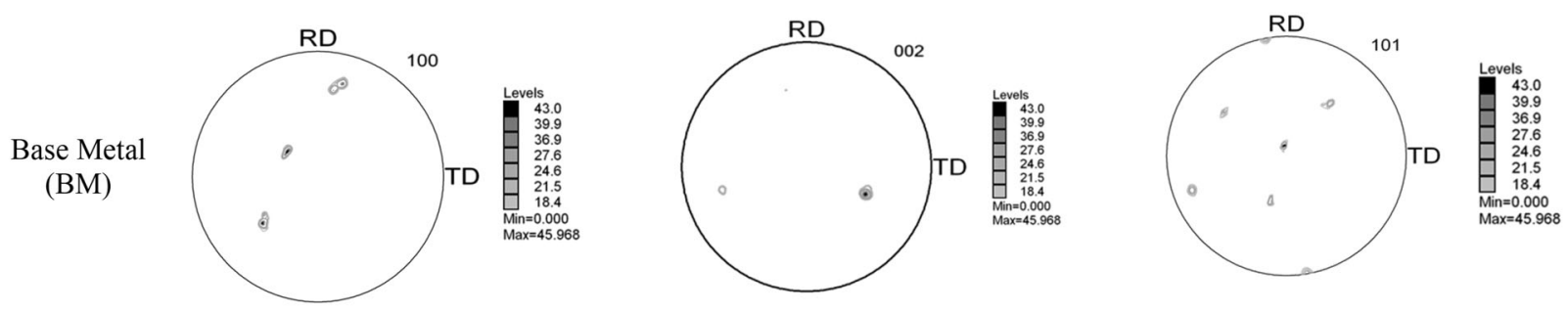

(a)
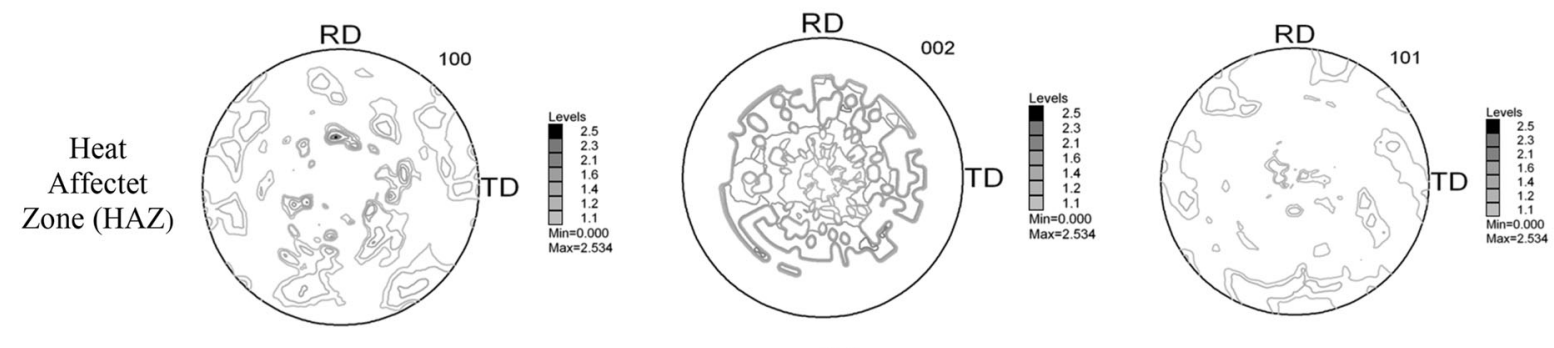

(b)

Fig. 9-Full calculated pole figures $\{\mathbf{1 0 1 0}\},\{\mathbf{0 0 0 2}\},\{\mathbf{1 0 1 1}\}$ in the $(a)$ base metal (BM) and $(b)$ in the heat-affected zone (HAZ).

elevated temperature deformation studies of $\mathrm{Mg}$ alloys show that at higher temperatures and lower strain rates, dynamic recrystallization (DRX) only involves the activation of slip systems. ${ }^{[40,44,45]} \mathrm{Yu}$ et al. ${ }^{[41]}$ showed that twinning in $\mathrm{Mg}$ can result in a drastic change in texture, e.g., extension twinning $\{10 \overline{1} 2\}\langle 10 \overline{1} 1\rangle$ reorients the basal pole around 86.3 deg. ${ }^{[4]}$ These non-basal slip mechanisms were only observed at elevated temperatures $\left[>453 \mathrm{~K}\left(>180^{\circ} \mathrm{C}\right)\right]$, which increased the formability of magnesium alloy at high temperature. ${ }^{[46,47]}$ In the nuggets, this texture is easily activated due to the correlation between plastic deformation and higher temperature. Our results agree with the literature results that indicate that the other slip mechanisms available in magnesium single crystals include (1010) prismatic and (1011) pyramidal slips. Sato et al. ${ }^{[17,18]}$ noted that the Goss orientation in the parent $6063 \mathrm{Al}$ was transformed into a shear texture component with two types of orientation in the center of the nugget. In our work, the study of the pole figures on both sides of the center (Figures 10(b) and (c)), i.e., in the fracture region (TMAZ) reveals that most of this zone possessed a texture with a strong tendency for the (0002) basal plane to align with the surface of the shoulder of the welding tool. This zone presents only the principal texture of the (0002) basal plane. This texture component was rotated around the "normal direction," the direction of the axis of pin. The tilt is different along the side. There is a strong tendency for the (0002) basal plane to tilt about $45 \mathrm{deg}$ from the TD on the AS and about $15 \mathrm{deg}$ from the TD on the RS. In the two zones, the presence of texture following the basal plane is expected because the preferential slip plane of $\mathrm{Mg}$ alloy with a HCP structure is known to be a $\{0001\}$ plane for plastic deformation at room temperature. ${ }^{[40]}$ According to the literature, the formation of texture following the (0002) basal plane is principally due to shear deformation rather than temperature. ${ }^{[41]}$ Indeed, the nature of this texture can be explained by the fact that the magnesium main disloca- tion slip system is the (0001) basal slip. It exhibits the lowest critical resolved shear stress $(\mathrm{CRSS}=0.45$ to $0.81 \mathrm{MPa}$ ) and can be activated at a low temperature. ${ }^{[19,20,47]}$ In the TMAZ zone, the change in texture mainly depends on the friction of the welding shoulder and the probe. This can explain the presence of only one component of the texture in the TMAZ zone due to a lower temperature. Both of these components were also observed by several authors ${ }^{[40]}$ including the rotational aspect of the texture component from the AS to the RS. Woo et al. ${ }^{[12,14]}$ studied the evolution of texture in AZ31 FSW by neutron diffraction. Their results revealed a significant variation in texture throughout different stages of FSW. Their investigation confirmed that the basal plane normal was parallel to the TD in the TMAZ. Based on these findings, the authors concluded that the SWZ is a complex zone that is not fully understood.

\section{F. Microhardness Characterization}

From the mechanical properties standpoint, the study of microhardness demonstrates that FSW welding induces particular profiles in the studied zones. Figure 11 shows the microhardness results, measured close to the surface on both sides of the linear weld in a profile including the BM passing through the HAZ and the welded zones. The same measurement has been realized along the same profile and at a depth around $200 \mu \mathrm{m}$. On the surface, the AZ91 friction stir-welded joint exhibits a significant microhardness evolution through the weld. The microhardness profile is symmetrical considering the center of the nugget. Significant variations (increase or decrease) of microhardness are measured in each transition region: BM and HAZ, HAZ and TMAZ, TMAZ and nugget. The higher microhardness values are measured in the $\mathrm{BM}$ and in the center of the HAZ $\left(90 \pm 5 \mathrm{Hv}_{0.2}\right)$. The TMAZ exhibits 

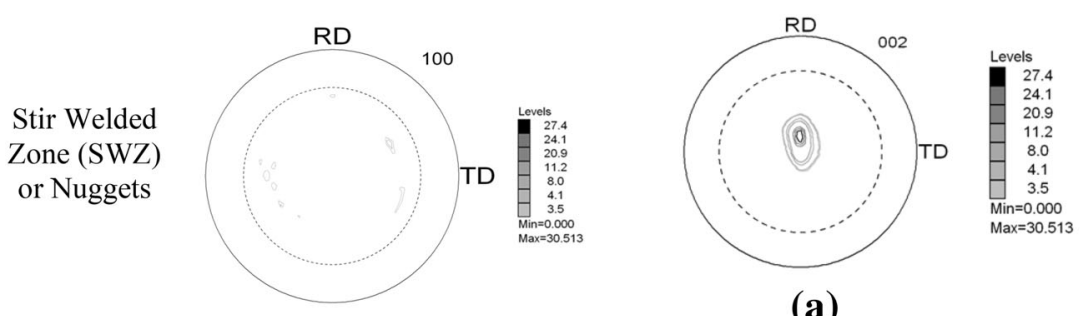

(a)
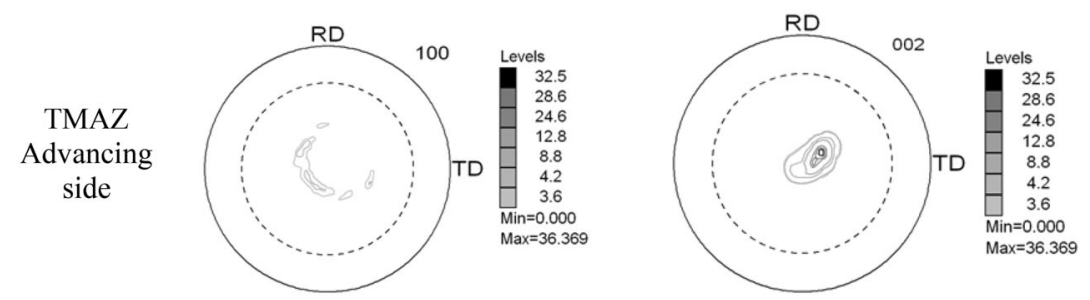

(b)

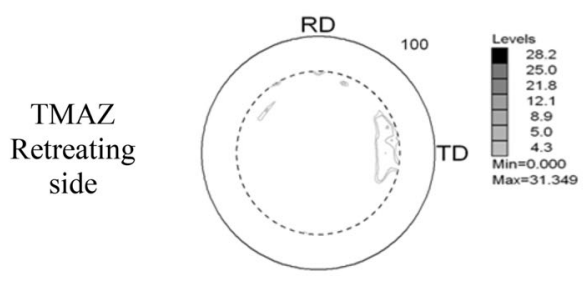

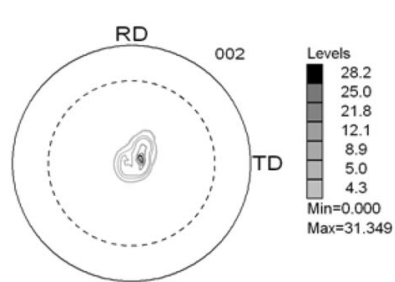

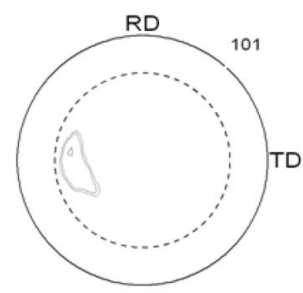

(c)

Fig. 10-Full calculated pole figures $\{\mathbf{1 0 1 0}\},\{\mathbf{0 0 0 2}\},\{\mathbf{1 0 1 1}\}$ in the $(a)$ stir-welded zone (SWZ) or nuggets, (b) TMAZ advancing side, $(c)$ TMAZ retreating side.

the lower values $\left(80 \pm 2 \mathrm{Hv}_{0.2}\right)$ and the NZ microhardness is intermediate $\left(85 \pm 4 \mathrm{Hv}_{0.2}\right)$. The results have enabled us to demonstrate that for microhardness that there are particular distributions in the different zones studied and that can be related to the modifications of microstructure, in particularly with the crystallographic texture. In the HAZ, near to the TMAZ zone, the microhardness is the same compared to the BM and sometimes it is slightly higher. This one can be explained by the presence of precipitates which are formed in this zone considered to be a zone of diffusion which contributes toward augmenting the microhardness. ${ }^{[48]}$ The microhardness in the TMAZ and in the nuggets is lower than in the BM, even though the size of the grains is smaller than in the BM. These results showed that the microhardness does not seem to conform only to the Hall and Petch effect ${ }^{[49]}$ which states that micro hardness increases as grain size decreases. This decreasing of microhardness can be explained in part by the influence of the dislocation density, residual stress variations within the weld and by the presence of the crystallographic texture. ${ }^{[49-51]}$ Studying down through the depth of the metal shows a much decreased hardness $\left(70 \mathrm{HV}_{0,2}\right)$ compared to the heart of the weld on the surface. But if we compare the center of the welded zone on the surface and in the depth, we observed a variation in microhardness with no variation in size. In the depth, this difference can be explained by the reduction in the amount of precipitates should lead toward a reduction in the micro hardness. ${ }^{[52]}$ On the surface, the increasing of the microhardness can be explained by hardening, the presence of twinning and orientation of grains. ${ }^{[15,53]}$ In this case two competing effects relating to the constraint-deformation response induced by the microhardness test are put into effect: the work hardening at the surface which is due to dislocations effect and the Basinski mechanism ${ }^{[44]}$ (reoriented regions and twinning). In our study we did not find any evidence of twinning, but of a marked and varying texture. The higher value of the microhardness of the surface of the welded zone compared to the welded zone in depth was attributed in part to the influence of the texture, by recalling that the hardness test induces a plastic deformation which follows the ND of the surface. However, the textured material is anisotropic compared to the plasticity. ${ }^{[15,19,44,53]}$

\section{G. Tensile Tests}

Figure 12 shows the results of tensile tests of a sample taken from the BM and one across the FSW region. Concerning mechanical properties, FSW resulted in a low loss in all the tensile properties (YS, UTS, and strain to failure) compared to the BM. These observations could be attributed to several factors. From the literature, for the FSW, the welds tensile mechanical properties were influenced by the manufacturing of the BM: cast, wrought, rolled alloys. Indeed, in the case of wrought magnesium alloys, FSW lead to a dramatic loss in all tensile properties. ${ }^{[7,54]}$ These results are consistent 


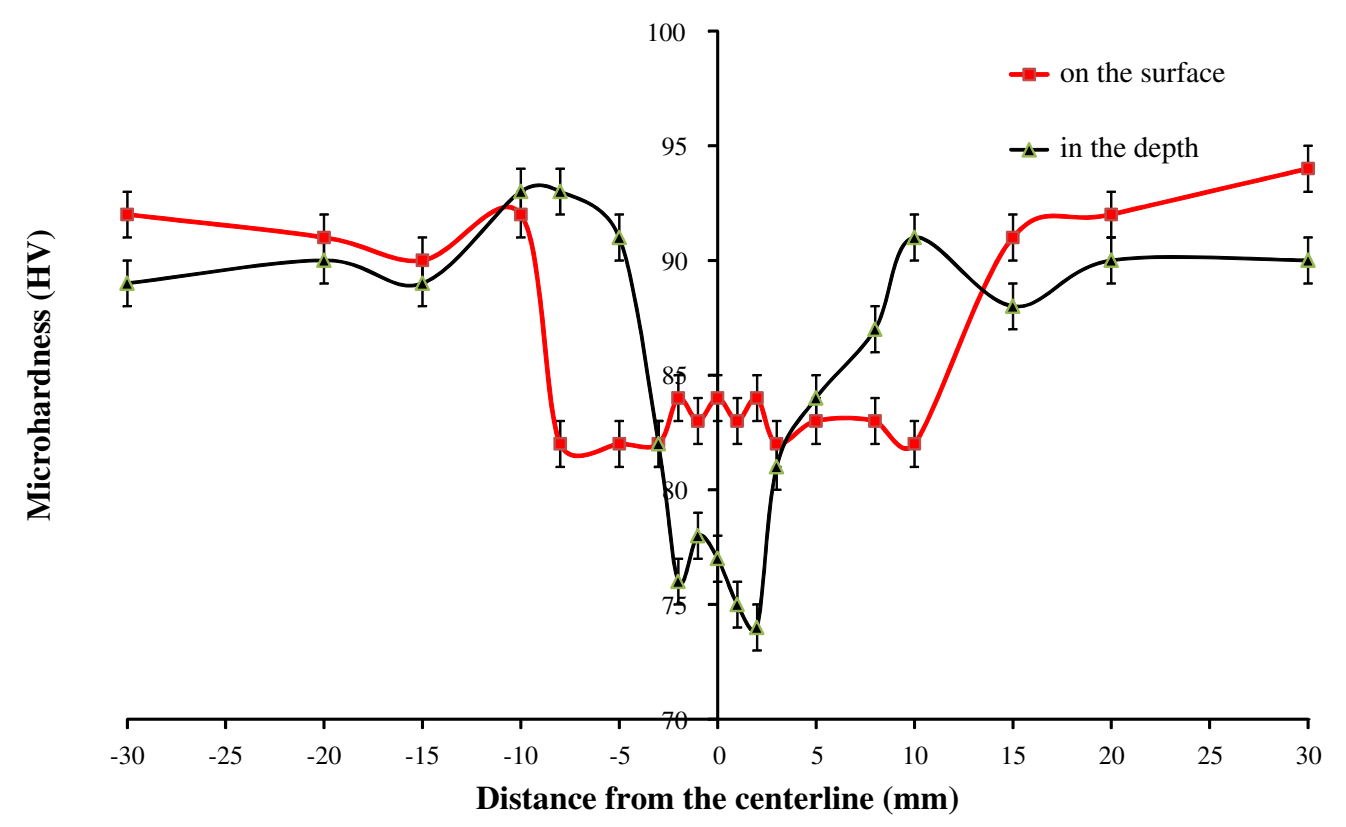

Fig. 11-Microhardness evolution through the base metal and the friction stir-welded zones.

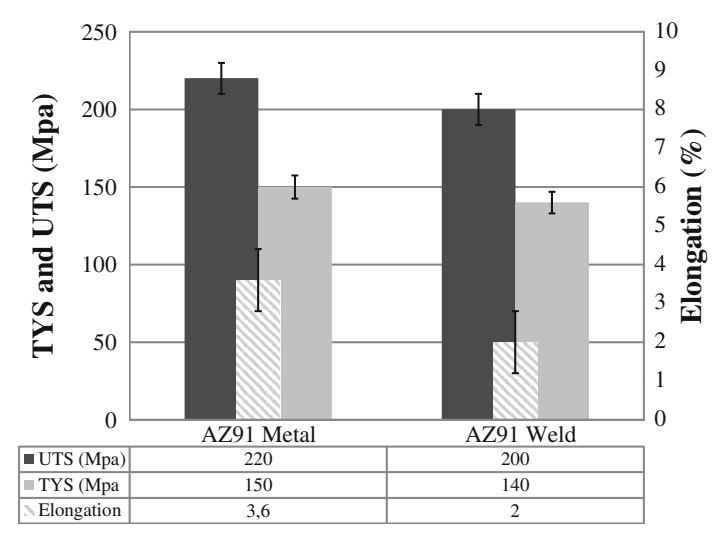

Fig. 12-Tensile tests in the base metal and in welded dumbbell specimen.

with previous studies such as Lim study, ${ }^{[55]}$ which showed that the welds tensile mechanical properties were not influenced only by the welding parameters used but by the manufacturing of the BM. This is right for the cast magnesium alloy such as our studied alloy and can be explain the obtained results. Various authors explained that the evolution of mechanical properties is generally attributed to microstructure gradients across FSW ${ }^{[17,56,57]}$ in particularly in the TMAZ. Moreover, during the tensile tests performed in this study, the fracture occurred in the area where the microstructural heterogeneity is high (i.e., TMAZ). ${ }^{[7,54,56]}$ Indeed, concerning the failure, our results showed that it occurred systematically in the TMAZ/nugget transition and principally on the AS butt weld. These observations can be too explained by the texture variations which are significant between the transition region and stir zone of the plate. The tensile behavior of the welded specimen including mainly the stir zone shows a significant decrease in elongation and a decrease in tensile strength compared to the BM. The correlation between the texture and tensile test results suggests that the drastic texture variation during FSW significantly affects tensile behavior of the FSW $\mathrm{Mg}$ alloy plate. ${ }^{[15,53]}$ This is consistent with Woo et al. study ${ }^{[14]}$ and Park et al. study ${ }^{[7]}$ which indicated that the large texture variation influenced the tensile properties of FSW and that the fracture was caused by the incompatible boundary between the TMAZ and the nugget..$^{[7,15,19,53,54]}$ Finally, the incompatible boundary between the transition region and the stir zone of FSW causes a fracture in the anisotropic hep magnesium alloy. ${ }^{[15,19,53,57]}$

\section{CONCLUSIONS}

The results of this study demonstrated the microstructural and anisotropic modifications induced by FSW in a thin sheet of magnesium alloy (AZ91). The characterization of FSW AZ91 optimized joints resulted in the following conclusions. The results of this study reveal that FSW induces the generation of several distinct zones with different microstructural, anisotropic, and mechanical properties. The following conclusions are drawn from this research.

1. Initially, the BM is composed of several phases such as the principal $\alpha-\mathrm{Mg}$ phase, the eutectic phase $\left(\alpha-\mathrm{Mg}, \beta-\mathrm{Mg}_{17} \mathrm{Al}_{12}\right)$ and the $\beta-\mathrm{Mg}_{17} \mathrm{Al}_{12}, \mathrm{Al}_{3} \mathrm{Mn}_{5}$ precipitates. The average grain size varies from 50 to $250 \mu \mathrm{m}$. The welded zone is composed of three 
distinct zones: the HAZ, the TMAZ, and the FSW. These zones are characterized by a number of microstructural and mechanical modifications.

2. The thermally affected zone (HAZ) no longer presents a eutectic phase but only the principal $\alpha-\mathrm{Mg}$ phase. The precipitates are localized mainly around grain boundaries in the matrix. In the HAZ, our results show that the size of the grains is smaller of those of the BM and the eutectic phase $(\alpha-\mathrm{Mg}+$ $\beta$ - $\left.\mathrm{Mg}_{17} \mathrm{Al}_{12}\right)$ is replaced by $\alpha-\mathrm{Mg}$ grains in the matrix and the $\beta-\mathrm{Mg}_{17} \mathrm{Al}_{12}$ phases were observed to be arranged along grain boundaries. This change was influenced by the heat of welding leading to some microstructural changes.

3. The welded zones feature fine grain sizes that are significantly smaller than those in the BM and the HAZ regions. In the TMAZ and in the SWZ, the grain size decreases significantly and reaches an average size between $2 \mu \mathrm{m}$ in the nuggets and 16 to $14 \mu \mathrm{m}$, respectively, in the advancing and RS. These zones are principally composed of an $\alpha-\mathrm{Mg}$ phase with $\beta$ - $\mathrm{Mg}_{17} \mathrm{Al}_{12}$ precipitates localized around the grain boundaries.

4. These two zones undergo intense plastic deformation with a moderate rise in temperature in the TMAZ and elevated temperature in the SWZ, which lead to a phenomenon of dynamic recrystallization, partial in the TMAZ and total in the nuggets zone. These differences in temperature explain why a fine and equiaxed recrystallized grain structure occupies the stir zone while a highly deformed grain structure consisting of subgrains is formed just outside the stir zone in the TMAZ with a large microstructure gradient.

5. Concerning the anisotropic properties, these zones are characterized by the presence of texture. The texture changes across the processing line in the friction-stir-welded AZ91-D magnesium alloy plate. The results showed that the texture variations are significant between the transition region and stir zone of the plate. Our results showed that the TMAZ presents the principal texture of the $\{0002\}$ basal plane, and in the center of the nugget, two types of texture orientation are observed: the $\{0002\}$ basal and the $\{10 \overline{1} 1\}$ pyramidal plane. These modifications have been explained by the nature of the plastic deformation as it is affected by temperature, which is moderate in the TMAZ and higher in the stir zone.

This study has demonstrated that in the case of heterogeneous deformation in a multiphase material complex changes in microstructural and mechanical properties occur due to FSW welding. These results are considered a basis for future investigation to better understand the microstructural and mechanical properties of welding materials. It should be noted that it is of interest to better understand the evolution of such materials' mechanical properties with respect to their microstructure, particularly their crystallographic texture and the evolution of the residual stresses.

\section{REFERENCES}

1. W.M. Thomas, E.D. Nicholas, and S.D. Smith: Proceedings of the TMS 2001 Aluminium Automotive Joining Sessions, 2001, p. 213.

2. R.S. Mishra and Z.Y. Ma: Mater. Sci. Eng. R, 2005, vol. 50, pp. 1-78.

3. H. Zhang, S.B. Lin, L. Wu, and J.C. Feng: Acta Metall. Sin., 2004, vol. 17, pp. 747-53.

4. M.M. Avedesian and H. Baker: Magnesium and Magnesium Alloys, ASM Speciality Handbook, ASM International, Materials Park, OH, 1999

5. R. Zettler, A.C. Blanco, J.F. dos Santos, and S. Marya: Magnesium Technology, TMS, San Francisco, CA, 2005, pp. 409-23.

6. T. Nagasawa, M. Otsuka, T. Yokota, and T. Ueki: Magnesium Technology 2000, The Minerals, Metals \& Materials Society, Warrendale, PA, 2000, pp. 383-87.

7. A. Scialpi, L.A.C. De Filippis, and P. Cavaliere: Mater. Des., 2007, vol. 28, pp. 1124-29.

8. K. Elangovan and V. Balasubramanian: Mater. Sci. Eng. A, 2007, vol. 459 , pp. $7-18$.

9. M. Boz and A. Kurt: Mater. Des., 2004, vol. 25, pp. 343-47.

10. K. Nakata, Y.G. Kim, and M. Ushio: Trans. Join. Weld Res. Inst., 2002, vol. 31, pp. 141-46.

11. K. Kumar and S.V. Kailas: Mater. Sci. Eng. A, 2008, vol. 485, pp. $367-74$.

12. W. Woo, H. Choo, D.W. Brown, P.K. Liaw, and Z. Feng: Scripta Mater., 2006, vol. 54, pp. 1859-64.

13. A.P. Reynolds, E. Hood, and W. Tang: Scripta Mater., 2005, vol. 52, pp. 491-94.

14. W. Woo, H. Choo, D.W. Brown, S.C. Vogel, P.K. Liaw, and Z. Feng: Acta Mater., 2006, vol. 54, pp. 3871-82.

15. I.C. Hsiao, S.W. Su, and J.C. Huang: Metall. Mater. Trans. A, 2000, vol. 33A, pp. 2169-80.

16. J.A. del Valle, M.T. Perez-Prado, and O.A. Ruano: Mater. Sci. Eng. A, 2003, vol. 355, pp. 68-78.

17. Y.S. Sato, H. Kokawa, M. Enmoto, and S. Jogan: Metall. Mater. Trans. A, 1999, vol. 30A, pp. 2429-37.

18. U.F.H.R. Suhuddin, S. Mironov, Y.S. Sato, and H. Kokawa: Mater. Sci. Eng. A, 2010, vol. 527, pp. 1962-69.

19. R. Gehrmann, M.M. Frommert, and G. Gottstein: Mater. Sci. Eng. A, 2005, vol. 395, pp. 338-49.

20. B.L. Mordike and T. Ebert: Mater. Sci. Eng. A, 2001, vol. 302, pp. $37-45$.

21. H. Watanabe, H. Tsutsui, T. Mukai, H. Ishikawa, Y. Okanda, M. Kohzu, and K. Higashi: Mater. Trans., 2001, vol. 42, pp. 1200-1205.

22. A. Luo: Can. Metall. Q., 1996, vol. 35, pp. 375-83.

23. S.W. Kalee, W.M. Thomas, and E.D. Nicholas: Magnesium Alloys and Their Applications, Wiley-VCH, New York, NY, 2000, pp. 175-190.

24. X. Cao, M. Jahazi, J.P. Immarigeon, and W. Wallace: J. Mater. Process. Technol., 2006, vol. 171, pp. 188-204.

25. A. Kouadri and L. Barrallier: Mater. Sci. Eng. A, 2006, vol. 429A, pp. 11-17

26. H.R. Wenk, K. Pawlik, J. Pospiech, and J.S. Kallend: Textures and Microstructures, 1994, vol. 22, pp. 233-60.

27. F.J. Humphreys and M. Hatherly: Recrystallization and Related Annealing Phenomena, Elsevier, Pergamon, 2004, pp. 555-56.

28. J.M. Fridy, K. Marthinsen, T.N. Rouns, K.B. Lippert, E. Nes, and O. Richmond: Proceedings of the 3rd International Conference on Aluminium, Trondheim, 1992, pp. 333.

29. K. Nakata, S. Inoki, Y. Nagano, T. Hashimoto, S. Johgan, and M. Ushio: Proceedings of the 3rd International Symposium on Friction Stir Welding, Kobe, Japan, 2001.

30. J.A. Esparza, W.C. Davis, E.A. Trillo, and L.E. Murr: J. Mater. Sci. Lett., 2002, vol. 21, pp. 917-20.

31. F. Caleyo, T. Baudin, M.H. Mathon, and R. Penelle: Eur. Phys. J. Appl. Phys., 2001, vol. 15, pp. 85-96.

32. Y.N. Wang, C.I. Chang, C.J. Lee, H.K. Lina, and J.C. Huanga: Scripta Mater., 2006, vol. 55, pp. 637-40.

33. W. Xunhong and W. Kuaishe: Mater. Sci. Eng. A, 2006, vol. 431, pp. 114-17.

34. R.P. Dobriyal, B.K. Dhindaw, S. Muthukumaran, and S.K. Mukherjee: Mater. Sci. Eng. A, 2008, vol. 477, pp. 243-49.

35. Y. Sirong, C. Xianjun, H. Zhiqiu, and L. Yaohui: J. Rare Earths, 2010, vol. 28, pp. 316-20. 
36. H.R. Wenk, K. Pawlik, J. Pospiech, and J.S. Kallend: Textures Microstruct., 1994, vol. 22, pp. 233-60.

37. J. Yan, Z. Xu, Z. Li, and L. Li: Trans. Nonferr. Met. Soc. China, 2005, vol. 15 (2), pp. 21-24

38. X. Wu, S.R. Kalidindi, C. Necker, and A.A. Salem: Acta Mater., 2007, vol. 55, pp. 423-32.

39. T. Al-Samman and G. Gottstein: Mater. Sci. Eng. A, 2008, vol. 490, pp. 411-20.

40. B. Beausir, L.S. Toth, and K.W. Neale: Acta Mater., 2007, vol. 55, pp. 2695-2705.

41. Z. Yu, H. Choo, Z. Feng, and S.C. Vogel: Scripta Mater., 2010, vol. 63 , pp. $1112-15$.

42. M.D. Nave and M.R. Barnett: Scripta Mater., 2004, vol. 51, pp. 881-85.

43. T. Mukai, M. Yamanoi, H. Watanabe, and K. Higashi: Scripta Mater., 2001, vol. 45, p. 89.

44. J.J. Fundenberger, M.J. Philippe, F. Wagner, and C. Esling: Acta Metall., 1997, vol. 45, pp. 4041-55.

45. Z.A. Matysina: Mater. Chem. Phys., 1999, vol. 60, pp. 70-78.

46. A. Galiyev, R. Kaibyshev, and G. Gottstein: Acta Mater., 2001, vol. 49, pp. 1199-1207.
47. S.R. Agnew and Ö. Duygulu: Int. J. Plast., 2005, vol. 21, pp. 1161-93.

48. C. Shaw and H. Jones: Mater. Sci. Eng. A, 1997, vols. 226-228, pp. 856-60.

49. W. Yuan, S.K. Panigrahi, J.-Q. Su, and R.S. Mishra: Scripta Mater., 2001, vol. 65, pp. 994-97.

50. J. Congleton and N.J. Petch: Acta Metall., 1966, vol. 14, pp. 1179-82.

51. R.M. Douthwaite and N.J. Petch: Acta Metall., 1970, vol. 18, pp. 211-16.

52. D.K. Xu, L. Liu, and Y.B. Xu: Mater. Sci. Eng. A, 2006, vol. 420, pp. $322-32$.

53. A.A. Salem, S.R. Kalidindi, R.D. Doherty, and S.L. Semiatin: Metall. Mater. Trans. A, 2006, vol. 37A, pp. 259-68.

54. W.B. Lee, Y.M. Yeon, K.K. Shae, Y.J Kim, and S.B. Jung: in Magnesium Technology, H. Kaplan, ed., TMS, Warrendale, PA, 2002, pp. 309-312.

55. S. Lim, S. Kim, C.G. Lee, C.D. Yim, and S.J. Kim: Metall. Mater. Trans. A, 2005, vol. 36A, p. 1609.

56. N. Afrin, D.L. Chena, X. Cao, and M. Jahazi: Mater. Sci. Eng. A, 2008, vol. 472, pp. 179-86.

57. A.H. Feng and Z.Y. Ma: Scripta Mater., 2007, vol. 56, pp. 397-400. 